\title{
Reviewer Acknowledgements for Journal of Biology and Life Scienc, Vol. 13, No. 1
}

Journal of Biology and Life Science (JBLS) would like to acknowledge the following reviewers for their assistance with peer review of manuscripts for this issue. Many authors, regardless of whether JBLS publishes their work, appreciate the helpful feedback provided by the reviewers. Their comments and suggestions were of great help to the authors in improving the quality of their papers. Each of the reviewers listed below returned at least one review for this issue.

\section{Reviewers for Volume 13, Number 1}

Bratko Filipic, (CIETO), Slovenia

Hoe Yin Chen, Tunku Abdul Rahman University College, Malaysia

Natalia Tkachuk, T.H. Shevchenko National University “Chernihiv Colehium”, Ukraine

Ragab A. El-Mergawi, National Research Centre, Egypt

Rajaa Ahmed Mahmoud, University of Basrah, Iraq

Xiaohuang Cao, Guangdong Ocean University, China

Kelvin Lee

Editorial Assistant

Journal of Biology and Life Science

Macrothink Institute

5348 Vegas Dr.\#825

Las Vegas, Nevada 89108

United States

Tel: 1-702-953-1852 ext.510

Fax: 1-702-420-2900

E-mail 1: jbls@macrothink.org

E-mail 2: jbls@macrothink.com

URL: http://jbls.macrothink.org 